\author{
Anna Dąbrowska-Kamińska \\ Uniwersytet Kardynała Stefana Wyszyńskiego \\ w Warszawie
}

\title{
Warianty odmiejscowych struktur przymiotnikowych w polskiej antroponimii
}

\section{Przedmiot opracowania}

Zbadaniu antroponimów, których podstawę stanowią nazwy miejscowe zakończone na -no, wywodzące się od nazw z formantem przymiotnikowym *-bn poświęcony jest niniejszy rozdział. Geneza tych nazw jako samodzielnej struktury toponimicznej wiąże się z przymiotnikami na *-bn. Henryk Borek, w monografii Zachodniosłowiańskie nazwy toponimiczne z formantem -bn- wykazał, że prasłowiański formant przymiotnikowy *-bn- , który w nazwach miejscowych występuje jako -no, -na, -ne, -ny, na gruncie polskim najbardziej żywotny jest w nazwach rodzaju nijakiego. Formy z -no są przy tym najczęstsze w północno-zachodniej części Polski, najrzadsze zaś na północnym Mazowszu [Borek 1968: 428].

Pod względem formalnym najliczniejszą grupę przymiotników relacyjnych tworzą formacje derywowane za pomocą przyrostka $*_{-b n b} \mathrm{i}^{*}$-bskb. Ten ostatni wyspecjalizował się m.in. w tworzeniu przymiotników od nazw miejscowych [Moszyński 2006: 279]. Natomiast pierwszy (*-bnъ) okazał się najbardziej ekspansywny w tworzeniu toponimów. Zapewne dlatego często spotykamy formant obok -in/-yn $<*$ inъ w nazwach miejscowych, które były pierwotnie przymiotnikami przynależnościowymi, dzierżawczymi, a z czasem przeszły do klasy rzeczowników, np. Rogalino, Trąbczyno, Kędzierzyno, Myślęcino [Lehr-Spławiński, Klemensiewicz, Urbańczyk 1955: 228].

\section{2. Źródła}

W niniejszym rozdziale scharakteryzowano nazwiska wywodzące się od przymiotników utworzonych od kresowych nazw miejscowych. Materiał toponimiczny pochodzi ze zbiorów Skarbu Koronnego Archiwum Akt Dawnych 
(AGAD-u w Warszawie), tj. Metryki Koronnej. Lustracje województwa ruskiego (czyli ziem: chełmskiej, halickiej, lwowskiej, przemyskiej) i województwa podolskiego pochodzą z XVIII w.. Wtedy to w zaborze austriackim i rosyjskim posiadanie nazwiska zostało prawnie usankcjonowane. Na przełomie XVIII i XIX wieku ukształtowała się także ukraińska antroponimia.

Analiza źródeł rękopiśmiennych pozwoliła na wyodrębnienie miejscowości, które najpewniej dały początek nazwom własnym osób tam zamieszkujących. Przykłady wybrane z dokumentów umożliwiają prześledzenie procesów kształtowania się nazw osobowych aż po nazwiska, odnotowane we współczesnych słownikach antroponimicznych, bowiem odniesienie do materiałów źródłowych pozwala poznać etymologię danego antroponimu i doprecyzować, czy jest odmiejscowa, czy odapelatywna.

\section{Prezentacja materiału}

Ze wspomnianych materiałów z lustracji przedstawiono 15 nazw miejscowych (zakończonych na -no) w pierwszej kolumnie tab. 1. W drugiej kolumnie umieszczono nazwiska zakończone na -ski/-cki pochodzące od tych toponimów. Uwzględniono warianty występujące w SEmot oraz SNuP. Przy interpretacji materiału zastosowano taksonomię Zofii Kowalik-Kalety, która w swojej monografii [zob. Kaleta-Kowalik 1981] podjęła problematykę kształtowania się staropolskich nazwisk odmiejscowych na ziemiach I Rzeczypospolitej, a więc także Małopolski i pogranicza południowo-wschodniego. Praca tej autorki powstała na podstawie kartoteki Stownika staropolskich nazw osobowych [zob. SSNO, 1965-1987] i zawiera m.in. podstawy teoretyczno-metodologiczne synchronicznego opisu budowy słowotwórczej nazw osobowych motywowanych przez nazwy miejscowe oraz charakterystykę budowy słowotwórczej nazw osobowych o cechach przymiotnikowych.

Tabela 1. Nazwy miejscowości i nazwiska odmiejscowe

\begin{tabular}{|l|l|l|}
\hline \multicolumn{1}{|c|}{$\begin{array}{c}\text { Nazwa } \\
\text { miejscowości }\end{array}$} & \multicolumn{1}{|c|}{ Nazwiska odmiejscowe z sufiksem -ski } & \multicolumn{1}{c|}{$\begin{array}{c}\text { Inne warianty nazwisk } \\
\text { odmiejscowych }\end{array}$} \\
\hline 1. Chmielno & Chmieliński, Chmielnikowski & Chmielnicki \\
\hline 2. Holowno & Hołowiński & Hołownicki \\
\hline 3. Kłodno & Kołodyński, Kłodziński, Kołodziński & Kłodnicki, Kłodecki \\
\hline 4. Komarno & Komarowski, Komarski & $\begin{array}{l}\text { Komarnicki, Komarnycky, } \\
\text { Komarnyckyj, Komarnyćka }\end{array}$ \\
\hline 5. Korosno & Korosiński, Krosieński, Krosiński & \\
\hline 6. Milno & Miln(i)owski, Miliński & Milnicki \\
\hline
\end{tabular}


Tabela 1

\begin{tabular}{|l|c|c|}
\hline 6. Milno & Miln(i)owski, Miliński & Milnicki \\
\hline 7. Okno & $\begin{array}{c}\text { Okniański, Oknieński, Okninski, Okniński, } \\
\text { Oknowski }\end{array}$ & Oknicki \\
\hline 8. Owadno & Owadowski & Porucki \\
\hline 9. Porudno & Porudzieński & Powicki \\
\hline 10. Powitno & Powitański & Rokitnicki \\
\hline 11. Rokitno & Rokiciański, Rokiciński & Rogoźnicki \\
\hline 12. Rogoźno & Rogozieński, Rogoziński, Rohozieński & Stolnicki \\
\hline 13. Stolno & Stoliński & Suszycki \\
\hline 14. Suszno & Suszyński, Suszuńska, Suszewski, \\
\hline 15. Zimno & Zuszowski & Zimnicki \\
\hline
\end{tabular}

Źródło: opracowanie własne (dotyczy wszystkich tabel).

\section{Omówienie materiału zawartego w tabeli 1}

Wspólną cechą nazwisk wymienionych w tab. 1 jest podstawa kończąca się na -no równa nazwie miejscowej oraz przymiotnikowe sufiksy -ski, -cki, które mogły ulegać rozszerzeniu o formanty przymiotnikowe -ic-, -eń- -iń-, -ow-, -ew-.

Sufiks -ic-\|-(s)ki łączy się z podstawami zakończonymi sufiksem -n- : Chmielnicki, Hołownicki, Kłodnicki, Komarnicki, Milnicki, Oknicki, Rokitnicki, Stolnicki.

Sufiks -eń-||-ski połączył się z podstawą na $-n(o)$ w antroponimie Oknieński : Okno. Zmiana morfonologiczna objęła wygłosową spółgłoskę podstawy, która uległa palatalizacji $(n: n ́)$.

Sufiks -iń-||-ski połączył się z podstawą zakończoną sufiksem - $n(o) \mathrm{w}$ antroponimach: Okniński, Zimniński. Zmiany morfonologiczne objęły tu wygłosowe spółgłoski podstawy, które uległy palatalizacji $(n: \dot{n})$.

W nazwiskach: Chmieliński, Hołowiński, Kłodziński, Kołodziński, Korosiński, Krosińnki, Miliński, Rokiciński, Stoliński sufiks iń-||-ski połączył się z podstawą, która uległa skróceniu o sufiks toponimiczny $-n(o)$. Zmiany morfonologiczne objęły wygłosowe spółgłoski podstawy, które uległy palatalizacji $n: n^{\prime}, d: d z^{\prime}, s: s^{\prime}, l: l^{\prime}, t: c^{\prime}$.

Sufiks -ow-||-ski połączył się z podstawą zakończoną sufiksem - $n(o) \mathrm{w}$ antroponimie: Oknowski : Okno.

Wśród nazw osobowych zakończonych sufiksem -cki-||-ski i motywowanych przez sufiksalne nazwy miejscowe, podstawa słowotwórcza niektórych nazwisk ulega skróceniu o sufiks toponimiczny - $n(o)$ [Kowalik-Kaleta 1981: 80]. Przykła- 
dami na skrócenie podstawy są: Porudno : Porucki, Powitno : Powicki, Kłodno : Kłodecki. Podobnie wśród nazw osobowych zakończonych rozszerzonym sufiksem -ow-/-ew-||-ski $i$ motywowanych przez sufiksalne nazwy miejscowe występują takie, których podstawa słowotwórcza ulega skróceniu o sufiks toponimiczny: -n(o) [Kowalik-Kaleta 1981: 60], np. Owadno : Owadowski, Suszno : Suszewski.

Fakultatywnie w przytoczonych w tab. 1 nazwach osobowych występuje palatalizacja spółgłosek zwartych $t: c^{\prime}, t: c, d: c(d z), d: d z^{\prime}$, por. Rokitnicki, Rokiciński : Rokitno, Powitański, Powicki : Powitno, Porucki : Porudno, Kołodyński, Kołodzieński : Kołodno.

Wszystkie miejscowości ujęte w tab. 1 znajdowały się w dawnych województwach ruskich. Można zauważyć w pochodnych od nich antroponimach cechy typowe dla języka ukraińskiego. Do fonetycznych różnic między postacią polską a ukraińską nazwisk należy m. in.: a) realizacja głoski szczelinowej $h \mathrm{w}$ miejscu prsł.* g, np.: Hołowiński, Hołowicki, Rohoziński; b) stwardnienie po spółgłosce n, np.: Komarnycky, Komarnyćka, Komarnyckyj; c) pełnogłos w nazwiskach: Hołowiński, Hołowicki, Kołodyński, Kołodziejski, co dowodzi wpływu wschodniosłowiańskiej fonetyki. W antroponimii polskiej paralelnie funkcjonują nazwiska o tożsamej podstawie prasłowiańskiej (por. ${ }^{*}$ golva,${ }^{*} k o l d a$ ), ale z metatezą, np. Kłodnicki, Kłodziński. Od wspomnianej prasłowiańskiej apelatywnej podstawy często wywodzi się określenie naturalnego obiektu topograficznego (pot. por. pagórkowate ukształtowanie czy wzniesienie terenu - przypominało głowę), które w procesie proprializacji staje się nazwą miejscową por. Głowno, Holovno.

Wśród wymienionych w tab. 1 nazwisk wystapiły także ukraińskie cechy słowotwórcze, jak np. obecność sufiksu -ckyj, (Komarnyckyj - tylko 1 osoba nosi to nazwisko w Polsce) funkcjonującego w antroponimii ukraińskiej. Zapis nazwiska Komarnyćka ze zmiękczeniem $c w$ sufiksie jest zgodny z wymową ukraińską. Nazwisko to również ma najniższą frekwencję (1).

\section{Prezentacja materiału porównawczego}

W niniejszym podrozdziale zagadnienia antroponimii kresowej zostały rozpatrzone z uwzględnieniem materiału porównawczego. Przeprowadzono bowiem analizę antroponimów powstałych od nazw miejscowych wyekscerpowanych ze słownika Dmytra Buczki [zob. Бучко 2001]. Interpretacji poddano nazwiska, które pochodzą od nazw miejscowych (zakończonych na -no) znajdujących się w granicach obecnej Ukrainy. Miejscowości te (jest ich 20) przytoczono w tab. 2 wraz z pochodnymi nazwiskami, które występują w dwóch ukraińskich słownikach antroponimicznych. P.P. Czuczka przedstawił w słowniku nazwiska mieszkańców Zakarpacia z 1946 roku [zob. Чучка 2005]. Zamieszkała tam rdzenna ludność jest jedyną i najdalej wysuniętą na południe poza Karpaty grupą wschodniosłowiańską. Julian Red'ko natomiast opracował nazwiska mieszkańców całej Ukrainy [zob. Редько 2007]. 
W pierwszej kolumnie podano nazwy miejscowości, w kolejnej umieszczono w porządku alfabetycznym nazwy osobowe, które od nich pochodzą i potwierdzone są w słowniku Red'ki, a w trzeciej kolumnie natomiast znalazły się formy nazwisk potwierdzone w słowniku Czuczki. Uwzględnione przez autorów inne nazwy miejscowości przywołane jako podstawy antroponimu - zostały także umieszczone $\mathrm{w}$ tabeli. Brak nazwiska $\mathrm{w}$ danym słowniku zaznaczono minusem (-). W kolejnej kolumnie, do wariantów nazwisk uznanych przez autorów za odapelatywne dodano współczesne nazwy dawnych miejscowości, które znalazły się w ukraińskich słownikach. Ostatnia kolumna zawiera nazwiska odmiejscowe, przytoczone jako materiał porównawczy ze słowników: ETSNP, SNuP oraz SEMot.

Tabela 2. Nazwiska pochodzące od nazw miejscowych zakończonych na -no

\begin{tabular}{|c|c|c|c|c|}
\hline \multirow{2}{*}{$\begin{array}{c}\text { Ojkonimy } \\
\text { w słowniku } \\
\text { D. Buczki }\end{array}$} & \multicolumn{4}{|c|}{ Nazwiska odmiejscowe w słowniku } \\
\hline & J. Red'ki & P. Czuczki & K. Rymuta & Uwagi \\
\hline 1. Bahno & Bahnjuk & - & $\begin{array}{l}\text { Bagnieński, Bag- } \\
\text { niński, Bagieński, } \\
\text { Bagiński }\end{array}$ & \\
\hline 2. Bubno & - & $\begin{array}{l}\text { Bubnyk, Bubno- } \\
\text { wycz, Bubnjak }\end{array}$ & Bubnowski & $\begin{array}{l}\text { Cz. podaje: Bu- } \\
\text { ben, Bubniv jako } \\
\text { odapelat. n. }\end{array}$ \\
\hline 3. Chorosno & - & - & $\begin{array}{l}\text { Krosieński, Krosiń- } \\
\text { ski, Krosnowski }\end{array}$ & \\
\hline 4. Dachno & $\begin{array}{c}\text { Dachnovs'kyj: } \\
\text { Dachnivka: } \\
\text { Dachniv }\end{array}$ & - & $\begin{array}{l}\text { Dachnowski, Da- } \\
\text { chowski }\end{array}$ & \\
\hline 5. Derno & $\begin{array}{l}\text { Dernivs'kyj: } \\
\text { Derniv }\end{array}$ & - & & - \\
\hline 6. Dubno & $\begin{array}{l}\text { Dubenec', } \\
\text { Dubens'kyj, } \\
\text { Dubenczuk, } \\
\text { Dubnevycz }\end{array}$ & $\begin{array}{l}\text { Dubyns'kyj: Duby- } \\
\text { no, Dubnycz, Dub- } \\
\text { nicki: Dubne }\end{array}$ & $\begin{array}{l}\text { Dubniewski, Dub- } \\
\text { niański, Dubnowski, } \\
\text { Dubnicki, Dubiński }\end{array}$ & \\
\hline 7. Hołowno & - & & $\begin{array}{l}\text { Hołowiński, Hoło- } \\
\text { wiecki, Hołowicki }\end{array}$ & $\begin{array}{l}\text { Cz.: Hołovenka, } \\
\text { Hołovec'kyj, - } \\
\text { yc'kyj (odapel.) }\end{array}$ \\
\hline 8. Horno & - & - & Hornowski: Hornów & \\
\hline 9. Horodno & Horodnjuk & - & $\begin{array}{l}\text { Horodeński, Horo- } \\
\text { dyński, Horodziński, } \\
\text { Chorodeński Choro- } \\
\text { dyński }\end{array}$ & \\
\hline
\end{tabular}


Tabela 2

\begin{tabular}{|c|c|c|c|c|}
\hline 11. Jawno & - & - & $\begin{array}{c}\text { Jawniewski, Jaw- } \\
\text { niowski }\end{array}$ & \\
\hline 12. Moroczno & - & - & & - \\
\hline 13. Porochno & $\begin{array}{l}\text { Porochons'kyj: } \\
\text { Porochon }\end{array}$ & Porochnavec' & & \\
\hline 14. Rovno & $\begin{array}{l}\text { Rovins'kyj, } \\
\text { Rovens'kyj, } \\
\text { Rovenczuk }\end{array}$ & $\begin{array}{c}\text { Rovyns'kyj, Ro- } \\
\text { wiński, Roviniec, } \\
\text { Rowieński: } \\
\text { Rivnja, Rivne }\end{array}$ & $\begin{array}{l}\text { Roweński, Rowień- } \\
\text { ski, Rówieński, Ro- } \\
\text { wiński, Rowski }\end{array}$ & $\begin{array}{c}\text { Rovno obecnie } \\
\text { nosi nazwę: Rivne }\end{array}$ \\
\hline 15. Sachno & $\begin{array}{l}\text { Sachnovs'kyj: } \\
\text { Sachnivka, } \\
\text { Sachnivci }\end{array}$ & & Sachnowski & \\
\hline 16. Stupno & $\begin{array}{l}\text { Stupnyc'kyj: } \\
\text { Stupnycja }\end{array}$ & $\begin{array}{c}\text { Stupnyc'kyj: Stup- } \\
\text { nycja }\end{array}$ & $\begin{array}{c}\text { Stupnicki, Stupniski, } \\
\text { Stupieński, Stu- } \\
\text { piński }\end{array}$ & \\
\hline 17. Svydno & $\begin{array}{l}\text { Svydnyc'kyj: } \\
\text { Svydnyk, } \\
\text { Svydnyky }\end{array}$ & - & $\begin{array}{l}\text { Swidnicki, Świdni- } \\
\text { cki, Świdniski }\end{array}$ & \\
\hline 18. Wereteno & - & $\begin{array}{c}\text { Werec'kyj, } \\
\text { Weryc'kyj, } \\
\text { Wereczans'kyj: } \\
\text { Werec'ki }\end{array}$ & $\begin{array}{l}\text { Wereszczyński: We- } \\
\text { reszczyn, Wereszyń- } \\
\text { ski :Wereszyn }\end{array}$ & $\begin{array}{c}\text { Werec'ki obecnie } \\
\text { Worota }\end{array}$ \\
\hline 19. Wikno & - & - & $\begin{array}{l}\text { Okniański, Oknień- } \\
\text { ski, Okninski, Ok- } \\
\text { niński, Oknowski, } \\
\text { Oknicki }\end{array}$ & \\
\hline 20. Zurno & - & - & & - \\
\hline
\end{tabular}

\section{Omówienie materiału zawartego w tabeli 2}

W przedstawionym materiale antroponimicznym sufiks $-s$ ' $k y j$ łączy się z podstawami zakończonymi sufiksami toponimicznymi -n-/-n(o) w następujących nazwach osobowych: Dubyn'skyj, Porochons 'kyj.

Sufiks -yc'-||-c’kyj łączy się z podstawami zakończonymi sufiksem - $n$-: Stupnyc'kyj : Stupno, Svydnyc'kyj : Svydno, Dubnyc'kyj : Dubno.

Jeżeli podstawa nazwy własnej miejscowej, np. Dubno, kończy się na dwie spółgłoski, to w pochodzącym nazwisku, tu: Dubens 'kyj pojawia się e wstawne. 
Sufiksy -ec'-//-yc'-||-kyj łączą się ze skróconą o sufiks toponimiczny -n-//-no podstawą słowotwórczą w nazwisku Hołovec 'kyj : Hołovno, Werec 'kyj, Weryc 'kyj : Wereteno (tu nastąpiła elizja, a następnie palatalizacja $t: c$ 'wygłosowej spółgłoski skróconej podstawy).

Sufiksy -ov-||-s'kyj oraz -iv-||-s'kyj połączyły się z podstawami zakończonymi sufiksem - $n(o)$ w antroponimach Dachnovs'kyj : Dachno, Dernivs 'kyj : Derno.

W niektórych nazwiskach podstawa słowotwórcza uległa skróceniu o sufiks toponimiczny: -no, np. Holovyc'kyj : Hotovno.

Sufiksy -eń-||-s 'kyj oraz -in-//-yn||-s 'kyj połączyły się ze skróconą o sufiks toponimiczny $n-/ /$-no podstawą słowotwórczą w antroponimach Rovieński : Rovno (tu zmiana morfonologiczna objęła wygłosową spółgłoskę skróconej podstawy, która uległa palatalizacji $\left.v: v^{\prime}\right)$, Rovins 'kyj, Rovyns 'kyj : Rovno.

W wymienionych powyżej antroponimicznych słownikach ukraińskich występują nazwiska na $-s^{\prime} k y j$, $-c^{\prime} k y j$, paralelne z polskimi formami na $-s k i,-c k i$. Do odmiejscowych zaliczane są także nazwiska z następującymi sufiksami: - 'ak , $-e v y c z,-e c$ ', -ovycz - 'uk, -yk. Oprócz nich w antroponimii ukraińskiej funkcjonują nazwiska odmiejscowe z sufiksami: -ak, -jak, -njak, -jan, -janyj.

Przy analizie wariantów odmiejscowych struktur przymiotnikowych należy wspomnieć o procesach takich, jak palatalizacja ostatniej spółgłoski podstawy $\mathrm{w}$ nazwiskach z sufiksami rozszerzonymi, asymilacji, a następnie: uproszczeniach, zmianach w sufiksach $-o>i, e>i$, wariantywności $o v: i v \mathrm{w}$ obrębie nazwiska o tej samej podstawie, pojawianiu się $e$ wstawnego. W słownikach ukraińskich trafiają się nazwiska w brzmieniu polskim, np. Rovieński, Dubnicki.

Odmiejscowe nazwiska Polaków przytoczone w tab. 2 są liczniejsze (54), niż ukraińskie (31). Występują zarówno z odprzymiotnikowymi sufiksami prostymi $-s k i,-c k i$, jak i ich wariantami rozszerzonymi o formanty, które podane zostały poniżej w porządku alfabetycznym wraz z ich statystyką: -ań-ski (3), -ec-ki (2), -eń-ski (11), -ew-ski (2), -ic-ki (2), -iń-ski (10), -ow-ski (7), -yń-ski (4).

Wyraźna „strefa produktywności formantu -no na Kresach, która ciągnie się od ziemi nowogrodzko-pskowskiej poprzez Białoruś na Wołyń”, została dość dawno ustalona [Borek 1968: 428]. Z materiałów z okresu międzywojennego ${ }^{1}$ wynika, że na Wołyniu istniało ponad 26 miejscowości, których nazwa kończyła się na -no, a na Podolu - tylko 7. Obecnie na Ukrainie nie istnieją miejscowości z tych lat, bądź mają zmienione nazwy. Natomiast nazwiska pochodzące od nich nadal funkcjonują $\mathrm{w}$ antroponimii polskiej. $\mathrm{Z}$ porównania danych ujętych $\mathrm{w}$ tabelach wynika, że pozostały pod własną, historyczną nazwą jedynie miejscowości: Chorosno, Holowno i Wikno.

${ }^{1}$ Nazwy miejscowości na Wołyniu i Podolu z okresu międzywojennego znajdują się na mapach i w indeksach dwóch Przewodników po Ukrainie Zachodniej, część I, Wotyń, 2005 r. i część II, Podole, 2006 r., wydanych w Pruszkowie przez Oficynę Wydawniczą Rewasz. Autorem obu części jest Grzegorz Rąkowski. 
Do fonetycznych różnic między postacią ukraińską a polską antroponimów należy pełnogłos, np.: Hołovec'kyj, Horodeński, Porochons 'kyj, Werec'kyj. Analiza materiału wykazała, że w antroponimii polskiej paralelnie funkcjonuja nazwiska o tożsamej podstawie prasłowiańskiej (por. *golva, *gordz, *porxъ), ale z metateza, np.: Prochnicki, Procheński.

Realizacja głoski szczelinowej $h \mathrm{w}$ miejscu prsł. ${ }^{*} g$ wystapiła w nazwiskach: Holovyc'kyj, Horodeński, Horodziński. Z kolei wzmocnienie $\chi$ przez zwarcie w ojkonimie Chorosno spowodowało przejście wspomnianego $\chi>k$, por. Chorosno $>$ Korosno.

W antroponimach Dubniewski / Dubnowski został zachowany prymarny system oboczności grup '-ew- po spółgłosce miękkiej i -ow- po spółgłosce twardej. Konkurencyjność tych grup widać natomiast w nazwiskach Jawniewski / Jawniowski, gdzie -ow- wystapiło również po spółgłosce zmiękczonej.

Założyłam, że nazwa miejscowości Vikno $\mathrm{z} v$ protetycznym w nagłosie (na Ukrainie) odpowiada nazwie miejscowej Okno w brzmieniu polskim. Obecność w tabeli licznych wariantów nazwisk na -ski typu Okniński zdaje się to potwierdzać.

Nazwa miejscowości Sachno może pochodzić od imienia Safon, Josafat. W antroponimii ukraińskiej funkcjonuje (zapewne dzięki procesowi przeniesienia) nazwisko Sachno.

W ukraińskich i polskich słownikach antroponimicznych nie zostały wymienione nazwiska wywodzące się od nazw miejscowych: Jajno, Moroczno, Zurno.

\section{Wnioski}

W rozdziale przeprowadziłam analizę antroponimów wspólnych dla obu języków: polskiego i ukraińskiego. Na materiał porównawczy złożyły się nazwy miejscowości istniejących obecnie na Ukrainie i potwierdzonych w słowniku Dmytra Buczki oraz ojkonimy ze źródeł XVIII-wiecznych należących do Metryki Koronnej (zbiory AGAD-u w Warszawie). Antroponimy odprzymiotnikowe pochodzące od nich zasługują na uwagę z powodu wariantywności form i ze względu na coraz mniejszą liczbę nosicieli, np. najniższą frekwencję (1) odnotowałam przy nazwiskach: Kłodyńska, Kłodynski, Kłodiński, Komarnyćka, Komarnyckyj, Komarnycky, Suszyńska.

Przyczyny ich wariantywności należy upatrywać w tendencji do unikania spółgłoskowych oraz samogłoskowych zmian morfonologicznych, które obejmują nie tylko wygłos podstawy (nazwy miejscowej), lecz także wygłos pnia podstawy, która najczęściej ulega modyfikacjom przez $e$ alternujące $\mathrm{z}$ zerem morfologicznym. Fakultatywnie występuje palatalizacja spółgłosek zwartych $t, d$ oraz $n$ [Kowalik-Kaleta 1981: 78]. Należy także wspomnieć o palatalizacji $v: v^{\prime}, s: s^{\prime}, z: z^{\prime}$.

Za źródło wariantywności form można uznać również odapelatywne pochodzenie nazwy miejscowej. Wynika ono ze stosowania przymiotników na *-bn 
w charakterze określeń toponimicznych, co wiązało się z faktem, że najstarszy zasób nazw z formantem *-bn o zasięgu ogólnosłowiańskim służył do szeroko pojętego określenia właściwości terenu. Pewne przykłady świadczą o tym, że dawne prymarne znaczenia zachowały się wyłącznie w nazwach własnych, np. *̌elo wzniesienie (n.m. Czelno) [Borek 1968: 351].

Historycznym procesem sprzyjającym powstawaniu wariantywnych form nazwisk odmiejscowych mogła być tendencja do nawarstwiania się nowszych formantów przymiotnikowych (zwłaszcza $-_{-}^{*}$ bnъ) na stare, już nieprzejrzyste przymiotniki (np. *blagz, *blagbnъ), które w ten sposób uzyskują formalny wykładnik swej przynależności do klasy przymiotników [Boryś 1998: 9-16]. Tendencja do unikania palatalizacji przez utrzymanie podstaw w niezmienionej postaci stanowiła (od staropolszczyzny) zjawisko wpływające na tworzenie form wariantywnych nazwisk. Konsekwencją było „nawarstwianie się na struktury z sufiksami prostymi - innych sufiksów, aż do pojawienia się w dobie średniopolskiej i nowopolskiej struktur wielosufiksalnych, które są rezultatem dalszego nakładania się na już istniejące formacje rozszerzone innych wykładników formalnych" [Gala 1985: 421].

Wariantywność nazwisk mogła być spowodowana także przez różne zapisy danego antroponimu.

\section{Wykaz skrótów}

ETSNP - Rymut Kazimierz, 1999-2001, Nazwiska Polaków. Słownik historyczno-etymologiczny, t. 1-2, Kraków

SNuP - Rymut Kazimierz, 2003, Stownik nazwisk użyanych w Polsce na poczatku XXI wieku, Kraków

SEMot - Stownik etymologiczno-motywacyjny staropolskich nazw osobowych, 1995-2000, Aleksandra Cieślikowa, Maria Malec i Kazimierz Rymut (red.), z. 3, 7, Kraków

SSNO - 1965-1987, Stownik staropolskich nazw osobowych, t. I-VII, Witold Taszycki (red.), t. VII - Suplement, Maria Malec (red.), Wrocław

\section{Bibliografia}

Borek Henryk, 1968, Zachodniosłowiańskie nazwy toponimiczne z formantem ,,-bn-”, Wrocław.

Boryś Wiesław, 1998, Kształtowanie się klasy przymiotników w epoce prasłowiańskiej, „Rocznik Slawistyczny" LI, 9-16.

Бучко Дтуtro, 2001, Інверсійний словник ойконімів Үкраӥни, Lublin.

Чучка Павло Павлович, 2005, Прізвища закарпатських украйнців: Історико-етимологічний словник, Видавництво „Світ”, Львів.

Dąbrowska-Kamińska Anna, 2006, Nazwiska Polaków typu: „Dilny”, „,Woronienko”, „,Tetera”, [w:] Zofia Abramowicz, Elżbieta Bogdanowicz (red.), Animizacja i apelatywizacja, Białystok, 363-374. 
Dąbrowska-Kamińska Anna, 2009, Odmiejscowe nazwiska Polaków w antroponimii kresowej, [w:] Ewa Dzięgiel, Anna Zielińska (red.), Polszczyzna za granica jako język mniejszości i języki mniejszościowe w Polsce, Warszawa, 73-93.

Dąbrowska-Kamińska Anna 2010, Nazwiska Polaków z sufiksem ,,-enko” w polskiej antroponimii, [w:] Romana Łobodzińska (red.), Nazwy własne a społeczeństwo, Wrocław, t. 1, 363-375.

Dąbrowska-Kamińska Anna, 2011, Nazwiska z sufiksem -uk, -czuk w antroponimii polskiej na podstawie wybranych przyktadów ze "Stownika nazwisk używanych w Polsce na poczatku XXI wieku" Kazimierza Rymuta, [w:] Maria Biolik, Jerzy Duma (red.), Chrematonimia jako fenomen wspótczesności, Olsztyn, 137-150.

Gala Sławomir, 1985, Polskie nazwy osobowe z podstawowym -l-/-l- w części sufiksalnej, Łódź.

Kowalik-Kaleta Zofia, 1981, Staropolskie nazwy osobowe motywowane przez nazwy miejscowe, Wrocław.

Lehr-Spławiński Tadeusz, Klemensiewicz Zenon, Urbańczyk Stanisław, 1955, Gramatyka historyczna języka polskiego, Warszawa.

Moszyński Leszek, 2006, Wstęp do filologii stowiańskiej, Warszawa.

Rąkowski Grzegorz 2005-2006, Przewodnik po Ukrainie Zachodniej, część I, Wotyń, część II, Podole, Pruszków.

Редько Юліян, 2007, Словник сучасних українських прізвищ, Львів.

Редько Юліян, 1966, Сучасні українські прізвища, Київ.

Anna Dąrowska-Kamińska

\section{Adjectival Structure Variants of Surnames of Place-Names Origin in Polish Anthroponomy}

(Summary)

The paper deals with the attempt to analyze the forming of some surnames types of place-name origin in Polish and Ukrainian anthroponymy. It is based upon the toponymic material included in the dictionary of oyconyms by Dmytr Buczko. Most of the anthroponyms analyzed have their word-formative base of place-name origin, as well as they have their adjectival equivalents. Some of these surnames occur in several variants like Holovno : Holowinski, Holowiecki, Holovec'kyj. The formal differences have been caused by morphological and phonetical processes. Different forms can also appear as a result of different writing formulas, or because of the various, place-name or appellative, origin of these names.

Słowa klucze: antroponim, toponim, procesy morfonologiczne.

Keywords: anthroponym, toponym, morphonemic processes. 